\title{
Spread-F during the magnetic storm of 22 January 2004 at low latitudes: Effect of IMF-Bz in relation to local sunset time
}

\author{
R G Rastogi ${ }^{1}$, H Chandra ${ }^{1, *}$, P Janardhan $^{1}$, Thai Lan Hoang ${ }^{2}$, Louis Condori ${ }^{3}$, \\ T K PANT ${ }^{4}$, D S V V D PRASAD ${ }^{5}$ and B REINISCH ${ }^{6}$ \\ ${ }^{1}$ Physical Research Laboratory, Ahmedabad 380 009, India. \\ ${ }^{2}$ Institute of Physics, Vietnam Academy of Sciences, Ho Chi Minh City, Vietnam. \\ ${ }^{3}$ Jicamarca Radio Observatory, Jicamarca, Peru. \\ ${ }^{4}$ Space Physics Laboratory, Thiruvananthapuram, India. \\ ${ }^{5}$ Department of Physics, Andhra University, Vishakhapatnam 530 000, India. \\ ${ }^{6}$ Digisonde International LLC 175, Lowell (Mass) 01854, USA. \\ *Corresponding author.e-mail: hchandra@prl.res.in
}

The paper describes the results of spread-F at low latitude stations around the world during the magnetic storm starting at 0130 UT on 22 January 2004. The storm can be divided into two phases, first phase up to 1000 UT when interplanetary magnetic field IMF-Bz was highly fluctuating around a small positive value and the second phase after a sudden large southward turning of IMF-Bz at $1030 \mathrm{UT}$. The first phase produced strong spread-F at Jicamarca, Sao Luis, and Ascension Island and caused complete inhibition of spread-F at Thumba and Waltair in India. It generated weak spread-F at Ho Chi Minh City in Vietnam and strong spread-F at Hainan and Chung Li. The strong spread-F at Hainan and Chung $\mathrm{Li}$ were caused by the positive IMF-Bz during the first phase of the storm and not by the negative pulse of IMF-Bz at $1000 \mathrm{UT}$.

\section{Introduction}

The unique geometry of the orthogonal horizontal electric field and the geomagnetic field gives rise to several distinct features of the equatorial and low latitude ionosphere, that are primarily controlled by the electrodynamics. The Equatorial Electrojet (EEJ), a band of intense daytime eastward current in the ionosphere $(100 \mathrm{~km})$ within $\pm 3^{\circ}$ latitudes from the magnetic equator (Chapman 1951) and the associated transparent type sporadic-E (Es-q) during daytime in the electrojet region (Matsushita 1951; Knecht 1959) are the two features observed close to the magnetic equator.
The latitudinal variation of noon foF2 with a trough centered at magnetic equator with two peaks at around $\pm 20^{\circ}$ magnetic latitudes (Appleton 1946), known as Equatorial Ionization Anomaly (EIA) is caused by the vertical drift of ionization near magnetic equator, followed by the plasma diffusion along the geomagnetic field lines to latitudes away from the magnetic equator.

Gouin and Mayaud (1967) described the phenomenon of $\mathrm{H}$ during daytime at an EEJ station decreasing below the night time level and named it counter electrojet (CEJ) suggesting a westward current. Rastogi et al. (1971) showed CEJ and disappearance of Es-q due to the reversal of

Keywords. Equatorial ionosphere; space weather; geomagnetic storm. 
ionospheric electric field as inferred from the ionospheric drift measurements at an electrojet station Thumba. This phenomenon is found to occur during geomagnetic quiet as well as disturbed periods (Chandra 1973).

Ionospheric drifts at Thumba showed a linear relationship with the daily range of $\mathrm{H}$ at Trivandrum (Chandra et al. 1971). The correlation improved with the difference between the ranges in $\mathrm{H}$ at Trivandrum and Alibag, a low latitude station. Rastogi and Chandra (1974) showed midday westward drift and midnight eastward drift increased monotonously with the increasing magnitude of the northward component of Interplanetary Magnetic Field (IMF). Thus an increase of southward component of IMF imposes an electric field in the equatorial ionosphere in anti-Sq direction.

Another interesting feature of the low latitude ionosphere is the occurrence of diffused and scatter F-region echoes in the night time hours. Booker and Wells (1938) showed from ionosonde observations at Huancayo, near magnetic equator, rapid rise of the F2 layer after sunset followed by the occurrence of diffuse echoes. The phenomenon was later observed at other equatorial stations: Singapore (Osborne 1952), Kodaikanal (Bhargawa 1958), Ibadan (Lyon et al. 1961) and Thumba (Chandra and Rastogi 1972a).

Chandra and Rastogi (1972a) showed that the equatorial spread-F (ESF) is basically of two types: (1) Range spread occurring during the post-sunset period, with diffusiveness along the horizontal part of the F-layer trace but the critical frequencies identifiable. (2) Frequency spread occurring during the post-midnight hours, with maximum spreading close to critical frequencies causing ambiguity in determining foF2. At times spreading extends to entire frequency range of the echoes causing ambiguity in determining both range and critical frequency. This was termed as complete spreading. The equatorial and low latitude spread-F are interconnected through a fountain of plasma irregularities similar to the daytime fountain of the plasma causing the equatorial ionisation anomaly.

The occurrence of spread-F at Huancayo showed a strong seasonal variation, with a maximum in December and a minimum in June (Chandra and Rastogi 1972b; Rastogi 1980). The seasonal variations of the occurrence of range spread and the delay in the evening reversal of the electric field were remarkably similar. Rastogi (1980) suggested that ESF irregularities occur when (1) strong upward plasma density gradient is present and (2) the daytime eastward ionospheric electric field continues for more than an hour after the F-layer sunset to allow the F-layer to rise and the irregularities to grow.
Plasma density irregularities covering a wide range of scale sizes, extending from hundreds of $\mathrm{km}$ to a fraction of a meter are associated with the phenomenon of ESF. The generalized RayleighTaylor instability, that includes the electric field and neutral winds along with gravitational term, is considered to be the primary process for the generation of intermediate scale irregularities. Large-scale plasma depletions thus generated rise fast to cover entire F-region including topside. Steep plasma density gradients then provide a seat for the generation of small-scale irregularities. Electric field gives rise to gradient drift instability under suitable plasma density gradients besides raising the F-layer to higher altitudes where growth rate due to gravitational term is higher.

Rastogi and Woodman (1978) showed that the range type of ESF can develop at any time of the night, other than the post-sunset period, if the vertical F-region drift reverses to upward direction due to an abnormal eastward electric field imposed in the night time ionosphere. There was about one hour delay between the reversal of the electric field and the appearance of ESF. An unusual reversal of vertical F-region drift from $-25 \mathrm{~m} / \mathrm{s}$ at $0330 \mathrm{LT}$ to $+65 \mathrm{~m} / \mathrm{s}$ at $0500 \mathrm{LT}$ and zonal E-region drift from -270 to $+225 \mathrm{~m} / \mathrm{s}$ was recorded by the VHF radar at Jicamarca at 0340 LT on 3 July, 1968 (Balsley and Woodman 1971). Rastogi and Patel (1975) showed that this event was associated with a large northward turning of the IMF. It was suggested that the solar wind moving with a velocity $\mathrm{V}$ across the IMF-Bz is equivalent to an interplanetary electric field $\mathrm{E}=-\mathrm{V} \times \mathrm{Bz}$. This field is transferred to the polar region and then to the equatorial latitudes without any delay. A northward turning of IMF-Bz would impose an electric field from dusk to dawn, i.e., eastward in the night side ionosphere. This event did produce ESF at Huancayo at 0445 LT after a delay of about one hour from the reversal of IMF-Bz (Rastogi 1977). Thus, it was clear that ESF is generated during the post-sunset period by the extension of eastward ionospheric electric field or at any other time of the night by eastward interplanetary electric field due to the northward turning of IMF-Bz.

Motivation for the present work is from the recent study of $\mathrm{Li}$ et al. (2009), who described the occurrence of spread-F at tropical latitude stations, Wuhan (magnetic latitude $20^{\circ} \mathrm{N}$ ) and Chung $\mathrm{Li}$ (magnetic latitude $13^{\circ} \mathrm{N}$ ), during the magnetic storm on 22 January 2004. Their observations are reproduced in figure 1 and their descriptions are quoted here, "On 22 January, the IMF Bz turned southward around $0957 \mathrm{UT}$ and showed a strong negative component of $-20 \mathrm{nT}$ at $1007 \mathrm{UT}$. The peak height of F-layers at the two stations 

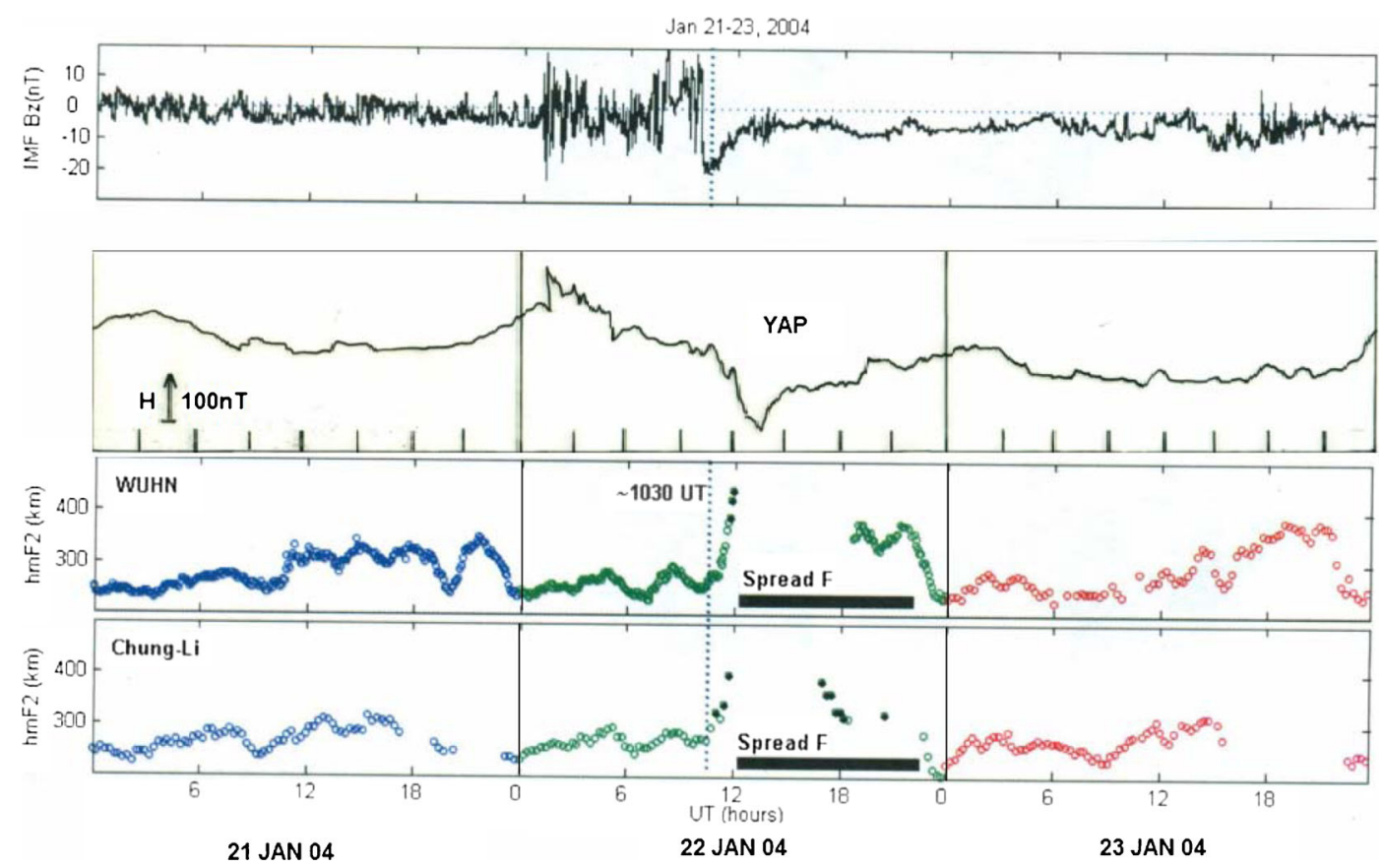

Figure 1. Daily variations of IMF-Bz, geomagnetic H field atYAP, hmF2 at WUHN and Chung-Li for 21-23 January 2004.

increased rapidly over $400 \mathrm{~km}$ during the period 10:30-12:00 UT which corresponds to local post sunset hours (18:30-20:00 LT)". They suggested that the simultaneous turning of IMF-Bz caused a prompt penetration of eastward electric field into low latitudes that augmented the normal ionospheric electric field lifting up the F-layer creating conditions favourable for the development of spread-F.

Rastogi (1980) showed that the ESF at Huancayo occurs only on the nights when the Sq dynamo electric field reverses from the daytime eastward to night-time westward direction at least 1-2 hours after the sunset at ionospheric levels. Rastogi (1983) also showed that the spread-F at tropical latitudes is due to the superimposition of additional off vertical h'F traces from the patches of irregularities drifting from the equatorial regions along the geomagnetic field lines. The tropical spread-F occurs about 2-3 hours after the full spread-F at equatorial latitudes.

Thus the generation of spread-F at tropical latitude stations, Wuhan and Chung Li, immediately at the sudden turning of IMF-Bz or the southward direction of IMF-Bz is not possible. The observations discussed by $\mathrm{Li}$ et al. (2009) are very interesting but their explanations are not acceptable by presently known relationship between IMF-Bz and spread-F. Thus, a critical examination of the event of 22 January 2004 at all available ionospheric stations was undertaken and the present paper describes the results of the investigations.

\section{Observations}

\subsection{Solar wind and geomagnetic field}

The various solar wind parameters and the SYM/H index are shown in figure 2 for 21 and 22 January 2004. During 21 January IMF-Bz showed small fluctuations around a mean magnitude of close to zero, solar wind speed was steady around $500 \mathrm{~km} / \mathrm{s}$, solar proton density was low around $4 / \mathrm{cm}^{3}$. Solar wind pressure was low around $2 \mathrm{nPa}$, interplanetary electric field (IEF) was low around zero and the SYM/H (ring current index) was negligibly small being about $-10 \mathrm{nT}$. Thus, the day was geomagnetically very quiet. At $0137 \mathrm{~h}$ UT on 22 January 2004 there was a sudden increase of solar wind speed from 500 to $700 \mathrm{~km} / \mathrm{s}$, solar wind density increased from 4 to $20 \mathrm{~cm}^{-3}$ and solar wind pressure increased to about $17 \mathrm{nPa}$; the $\mathrm{SYM} / \mathrm{H}$ index increased to positive $40 \mathrm{nT}$. The IMF-Bz started large fluctuations between about 10 and $-10 \mathrm{nT}$. Between 07 and $10 \mathrm{UT}, \mathrm{Bz}$ was largely positive with values of up to $10 \mathrm{nT}$. Thus a positive storm was generated till 1000 UT. Around 1000 UT, the IMF-Bz sharply turned southward $(-20 \mathrm{nT})$ and soon started recovery to $-5 \mathrm{nT}$ level at about 14 UT. At the same time SYM/H started decreasing and attained a value of $-140 \mathrm{nT}$ at $1300 \mathrm{UT}$. Corresponding to the changes in the IMF-Bz, IEF increased following the sudden increase in the solar wind parameters. It showed fluctuations in polarity in accordance to the changes in the polarity of 


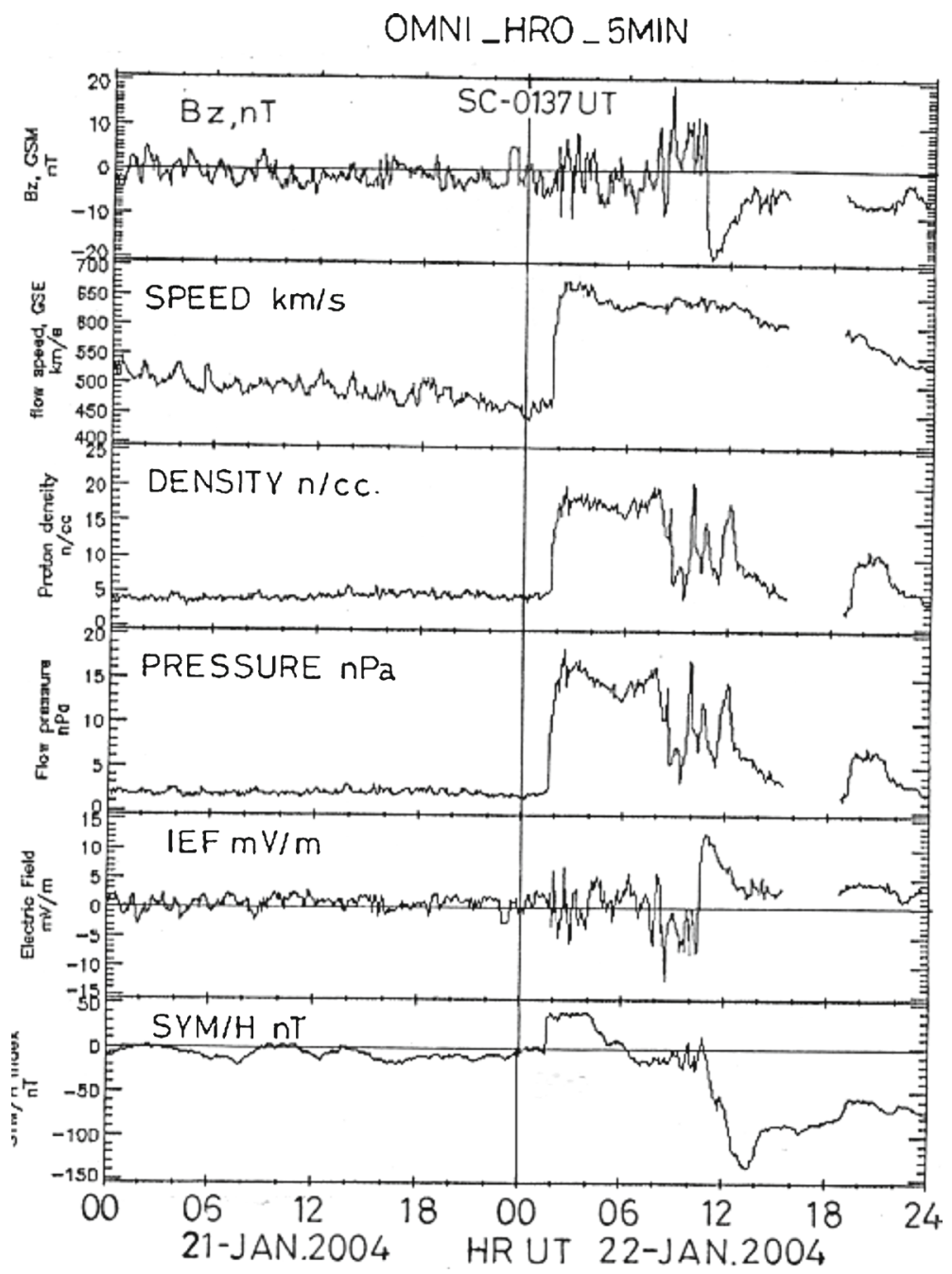

Figure 2. Daily variations of IMF-Bz; solar wind parameters speed, density and pressure; interplanetary electric field (IEF) and SYM/H index for 21-22 January 2004.

Table 1. Co-ordinates of the stations whose data are utilized.

\begin{tabular}{rllrrrr}
\hline & & & Geog. Lat. & Geog. Long. \\
No. & \multicolumn{1}{c}{ Station } & Code & $\begin{array}{c}{ }^{\circ} \mathrm{N} \\
{ }^{\circ} \mathrm{E}\end{array}$ & $\begin{array}{c}\text { Inclination } \\
{ }^{\circ} \mathrm{N}\end{array}$ & $\begin{array}{c}\text { Local time } \\
\text { UT }+ \text { hr }\end{array}$ \\
\hline 1 & Madimbo & MU & -22.4 & 30.9 & 0.5 & 2.1 \\
2 & Alibag & ABG & 18.6 & 72.9 & 25.7 & 4.9 \\
3 & Tirunelveli & TIR & 8.7 & 77.8 & 0.6 & 5.2 \\
4 & Waltair & WLT & 17.7 & 83.3 & 22.6 & 5.6 \\
5 & Chumphon & CHU & 10.7 & 99.4 & 6.6 & 6.6 \\
6 & Ho Chi Minh City & HCM & 10.5 & 106.3 & 6.2 & 7.1 \\
7 & Hainan & HAN & 19.4 & 109.0 & 26.2 & 7.3 \\
8 & Chung Li & CNG & 24.9 & 121.1 & 36.0 & 8.1 \\
9 & Okinawa & OKN & 24.8 & 125.3 & 35.5 & 8.4 \\
10 & Kwajalein & KJ & 9.4 & 167.0 & 15.3 & 11.1 \\
11 & Piura & PIU & -5.1 & 278.9 & 1.1 & -5.4 \\
12 & Huancayo & HUA & -12.0 & 284.7 & 1.1 & -5.1 \\
13 & Jicamarca & JIC & -12.0 & 283.2 & -4.6 & -3.1 \\
14 & Sao Luis & SAO & -2.6 & 315.8 & -11.6 & -0.9 \\
15 & Ascension Island & ASC & -8.0 & 345.6 & & \\
\hline
\end{tabular}



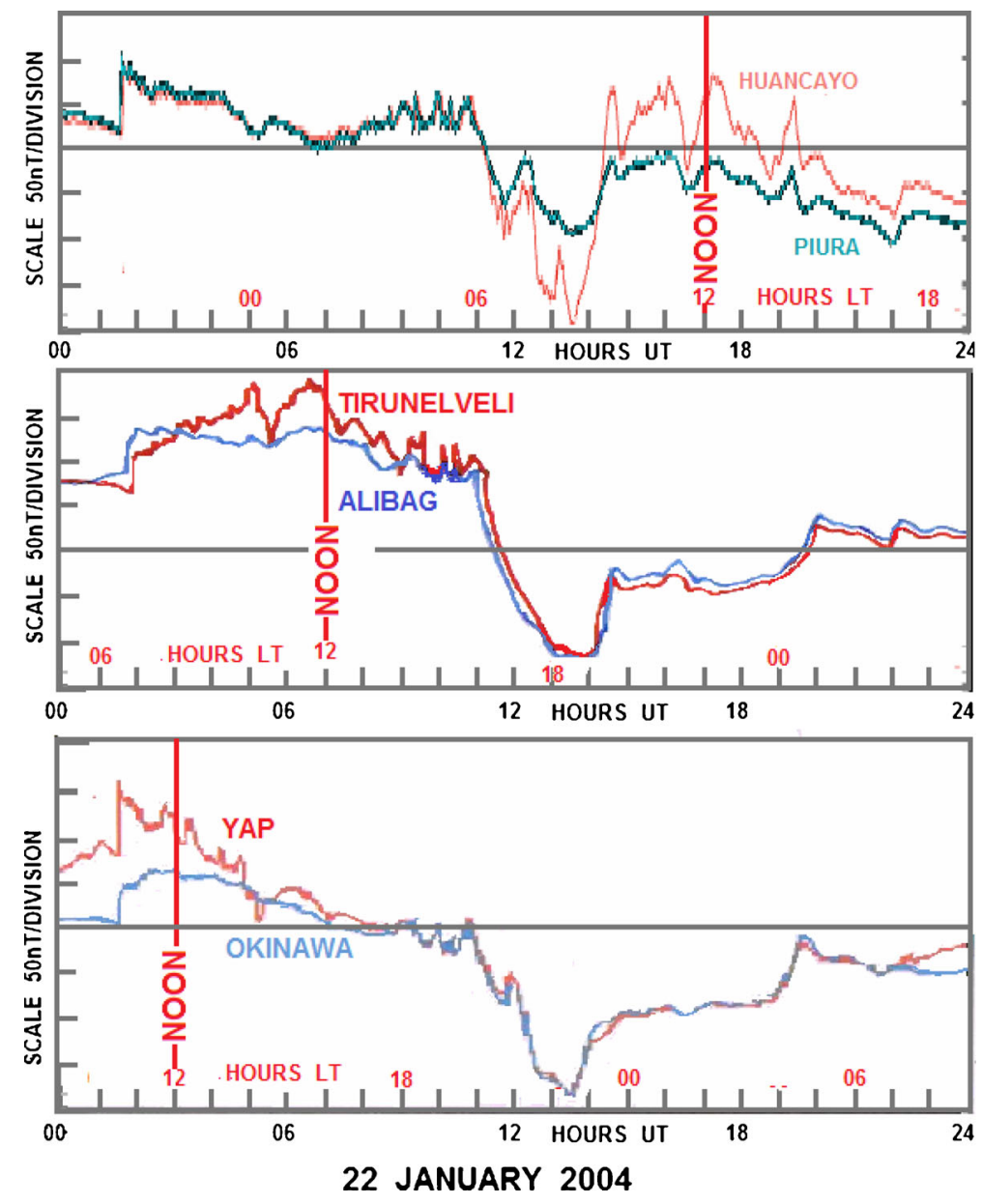

Figure 3. Daily variations of the geomagnetic $\mathrm{H}$ field at a pair of stations (one near magnetic equator and another away from magnetic equator) for different longitude sectors. The stations are Huancayo and Piura (American), Addis Ababa and Eilat (African), Tirunelveli and Alibag (Indian) and Yap and Okinawa (Far East).

IMF-Bz. Between about 08 UT and 1000 UT, IEF was negative $(-10 \mathrm{mV} / \mathrm{m})$ and reversed suddenly to about $10 \mathrm{mV} / \mathrm{m}$ at about $1000 \mathrm{UT}$. Thus the interplanetary electric field remained negative for 2-3 hours before 1030 UT and following the southward turning of IMF-Bz at 1000 UT was positive for $2-3$ hours. The Kp index (not shown here) varied up to 7. Thus 00-10 UT represented a disturbed period.

The geographic coordinates, magnetic inclination, and the local time standard of the stations whose data are used in the present analyses are listed in table 1.

Figure 3 shows the $\mathrm{H}$ component of the magnetic field for 22 January 2004 at pairs of equatorial and off-equatorial latitudes for different longitude zones: Hunacayo and Piura for American $\left(75^{\circ} \mathrm{W}\right)$ sector, Tirunelveli and Alibag for Indian sector $\left(75^{\circ} \mathrm{E}\right)$ and Yapanol and Okinawa for East Asian sector $\left(125^{\circ} \mathrm{E}\right)$. Along American sector, there was a strong counter electrojet between 12 and $14 \mathrm{~h}$ UT corresponding to 07-09 $\mathrm{h}$ local time; when $\triangle H$ (HUA) values were less than corresponding $\triangle H$ (PIU) values. During the rest of the day strong electrojet was present when values of $\triangle H$ at HUA were significantly larger than $\triangle H$ at PIU. Along the Indian sector, the storm started almost at local sunrise and $\triangle H$ (TIR) values before mid-day were larger than $\triangle H$ (ABG) suggesting normal equatorial electrojet. However, in the afternoon the values of $\triangle H$ (TIR) were only slightly larger than $\Delta H$ (ABG) suggesting a weak electrojet. Along East Asian sector, the storm started at $09 \mathrm{~h}$ local time and $\triangle H$ (YAP) values were much larger than $\triangle H$ $(\mathrm{OKN})$ values suggesting a strong equatorial electrojet. Thus the first phase resulted in weakening of the electrojet in the Indian sector in the afternoon.

\subsection{Ionosonde observations}

2.2.1 American sector $75^{\circ}$ and $45^{\circ} \mathrm{W}$ : First phase of the storm on 21 January, 2004

The two equatorial ionospheric stations operating during January 2004 were Jicamarca, Peru $\left(75^{\circ} \mathrm{W}\right)$ 
and Sao Luis Brazil $\left(44.2^{\circ} \mathrm{W}\right)$. Both these stations are close to the magnetic equator. The ionograms at Jicamarca shown in figure 4 were very clean without any spread-F during the entire night of 2021 January 2004. The F-layer steadily descended with h'F of $380 \mathrm{~km}$ at 0200 UT to $250 \mathrm{~km}$ at 1000 UT. On the night of 21-22 January 2004 strong equatorial spread-F was recorded during the period of the first phase of the storm suggesting imposition of strong prompt penetration eastward electric field (night time) in the ionosphere over the region. In figure 5 are shown the ionograms at Sao Luis (longitude $45^{\circ} \mathrm{W}$ ) on the night of $21-22$ January 2004. Following the height rise strong spread-F was seen from 2300 to 0600 UT (2018-0318 LT).

\subsubsection{Second phase of the storm}

Next, we examine the ionograms at American sector during the period 06 to $12 \mathrm{~h}$ UT on 21 and 22 January 2004. As indicated earlier strong counter electrojet event was recorded during this period on 22 January 2004. The ionograms for Jicamarca are shown in figure 6. On 21 January, strong Es-q were recorded at $0800 \mathrm{LT}$ and thereafter at 0900 and 1000 LT. On 22 January no Es-q echoes were observed on the ionograms in the morning till 0900 LT (1400 UT) because of the counter electrojet event indicated earlier. The ionograms on 22 January 2004 at Sao Luis in figure 7 also show no Es-q from 1300 to 1500 UT (1000-1200 LT). These
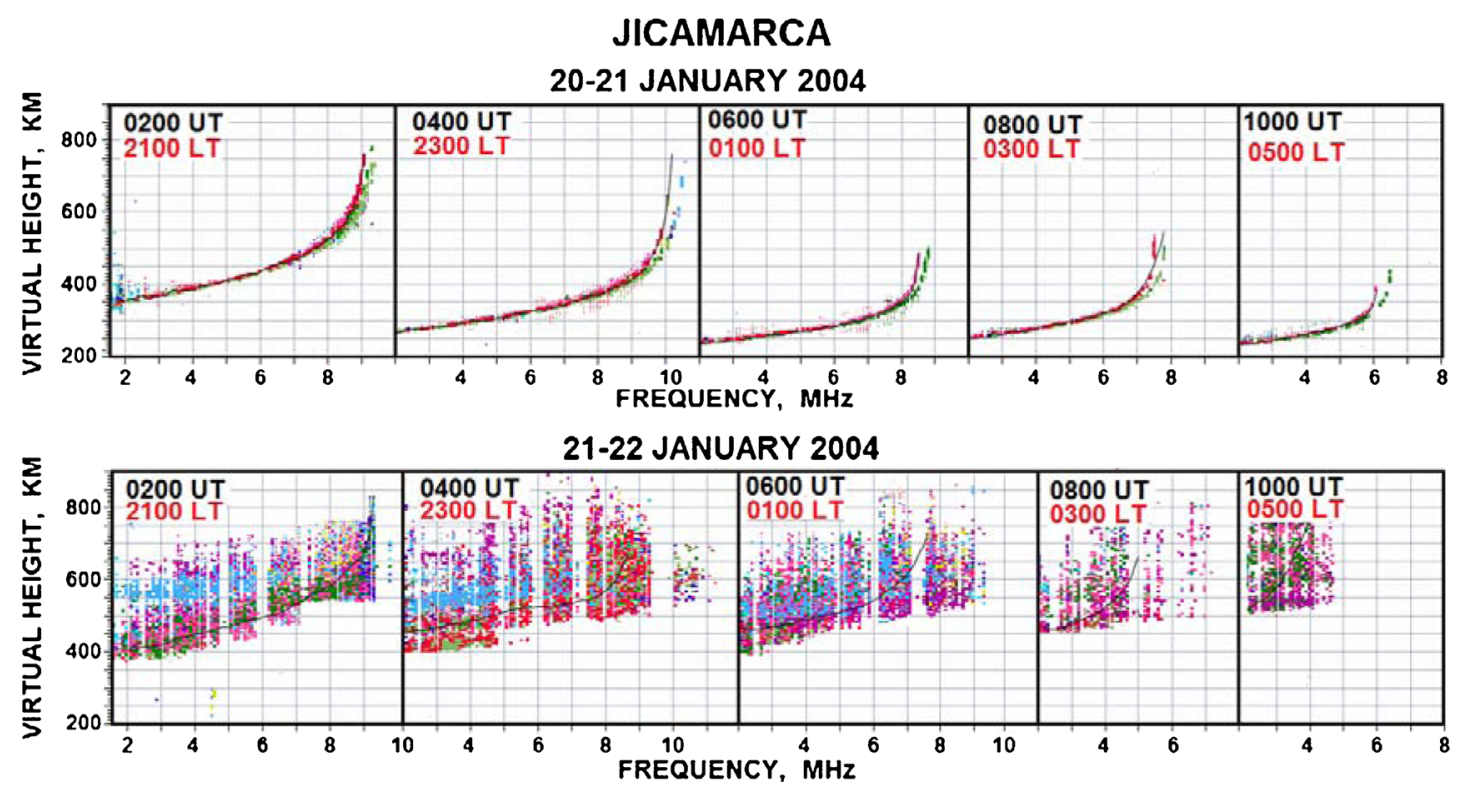

Figure 4. Selected ionograms at Jicamarca during the local nights of January 20-21, 2004 and January 21-22, 2004.
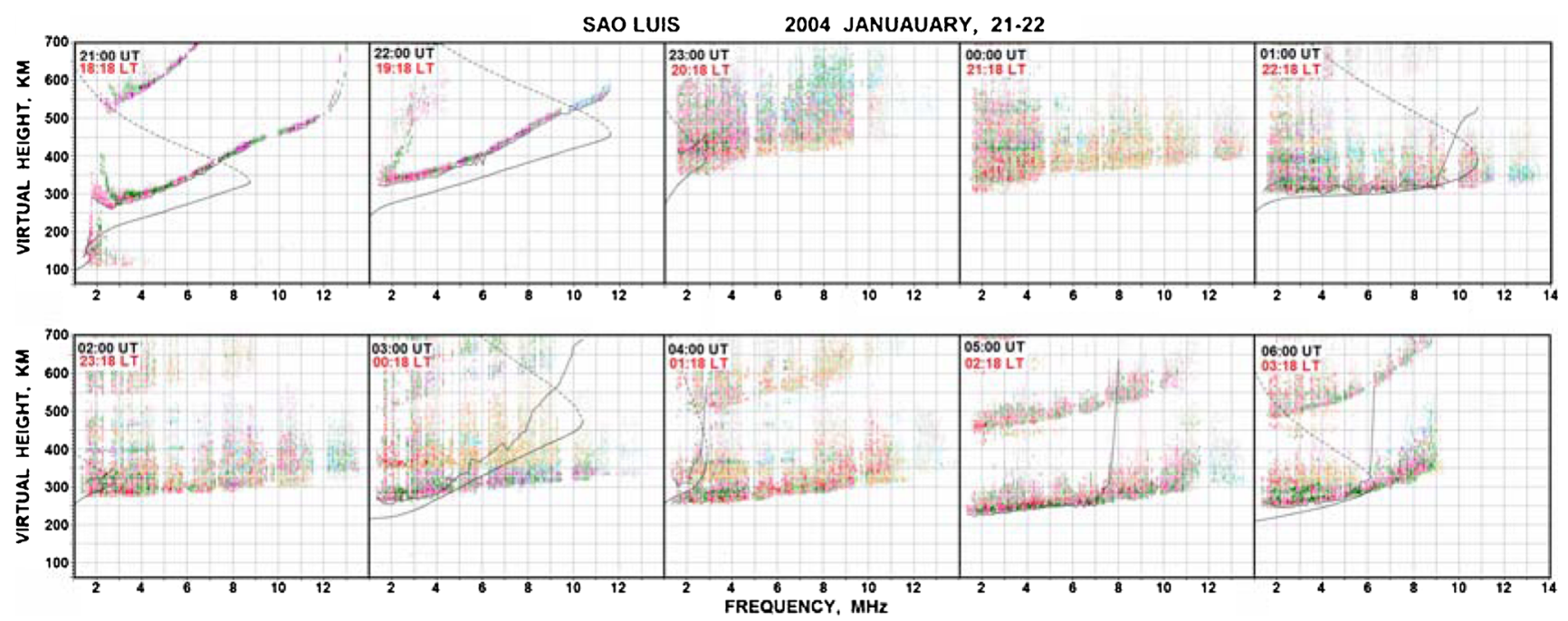

Figure 5. Selected ionograms at Sao Luis during the night of January 21-22, 2004. 


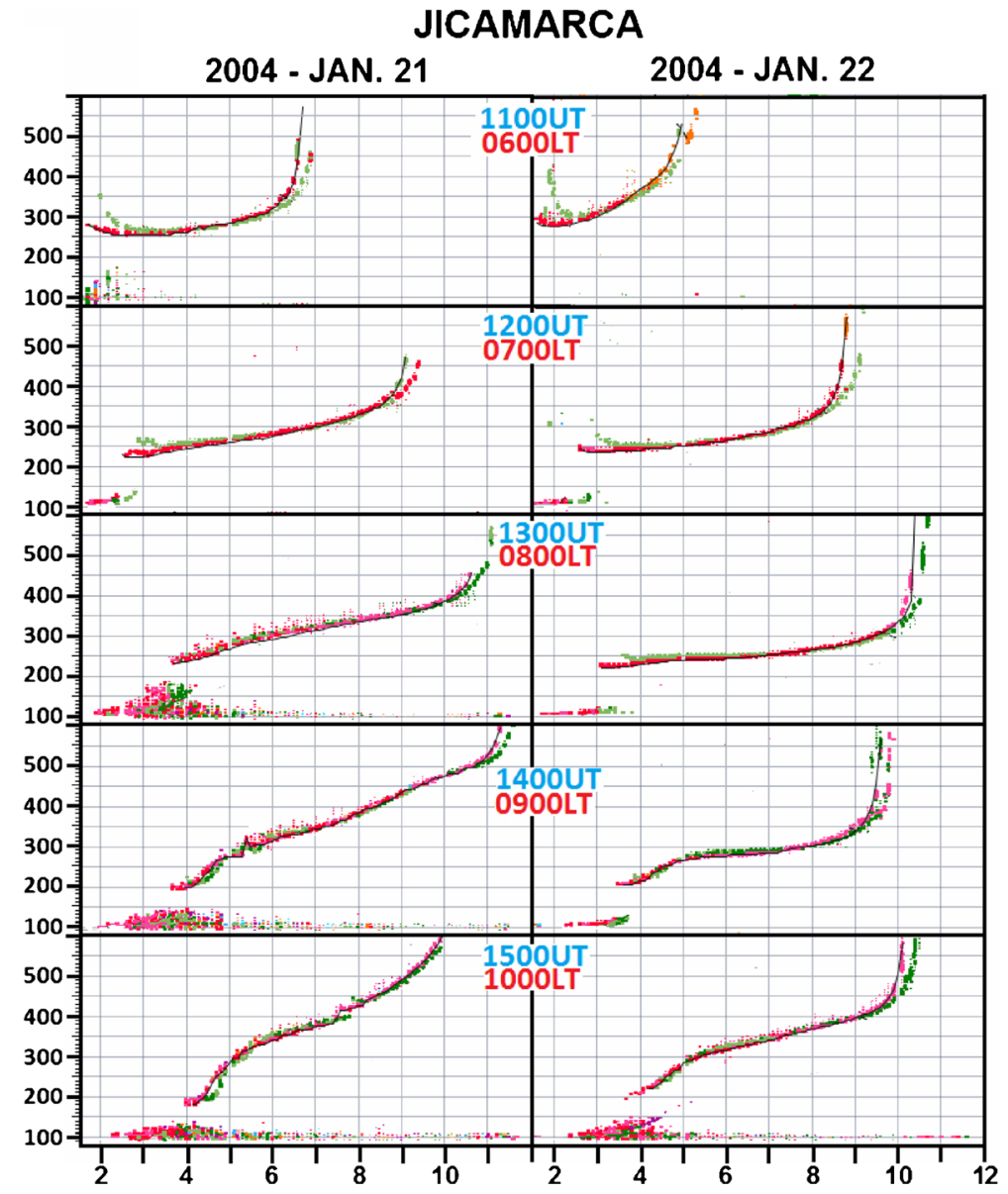

Figure 6. Selected local daytime ionograms at Jicamarca during January 21-22, 2004.

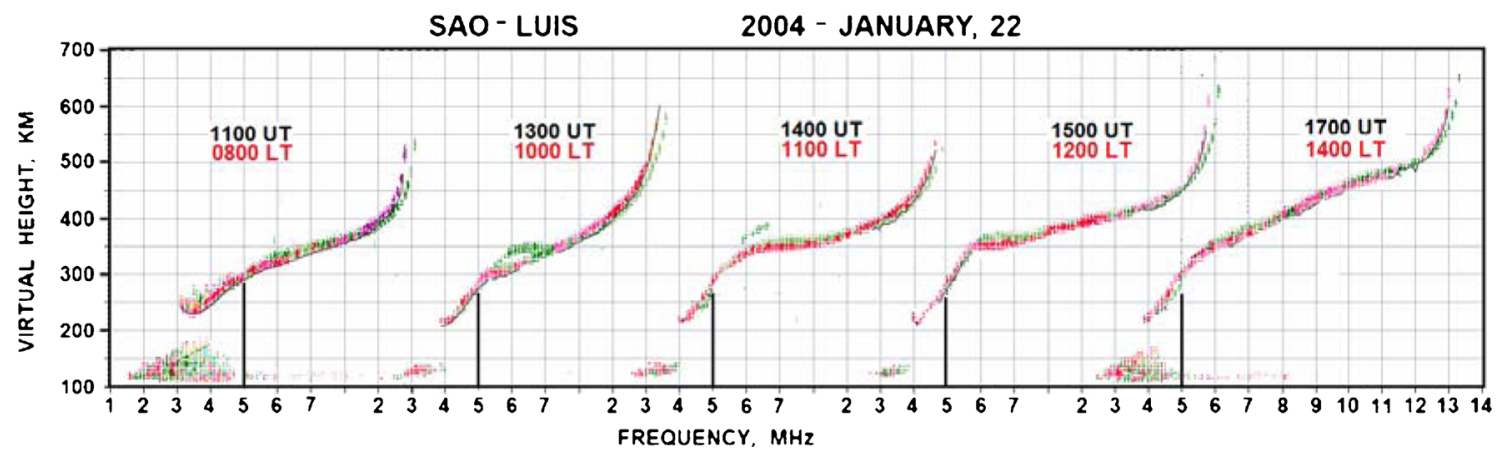

Figure 7. Selected local daytime ionograms at Sao Luis during January 22, 2004.

observations indicate that along the American longitude sector westward electric field was present in the morning hours. IMF-Bz turned southward around 1000 UT sharply but immediately started recovering to northward.

\subsection{Ascension Island}

Next moving eastward we have the data at low latitude station Ascension Island (ASC) in the
Atlantic Ocean having an inclination of $43^{\circ} \mathrm{S}$. The ionograms at ASC on 21 and 22 January 2004 are shown in figure 8 . On the evening of 20 January 2004 there was a small rise of h'F around 01 UT but no spread echoes were observed. On the evening of 21 January 2004 there was a mild rise of h'F after 2014 LT and spread-F were observed at 2044 LT, which intensified at 2114 LT. The layer descended at 2129 LT and no spread-F were seen on the ionograms at 2129 and 2214 LT. This suggested 


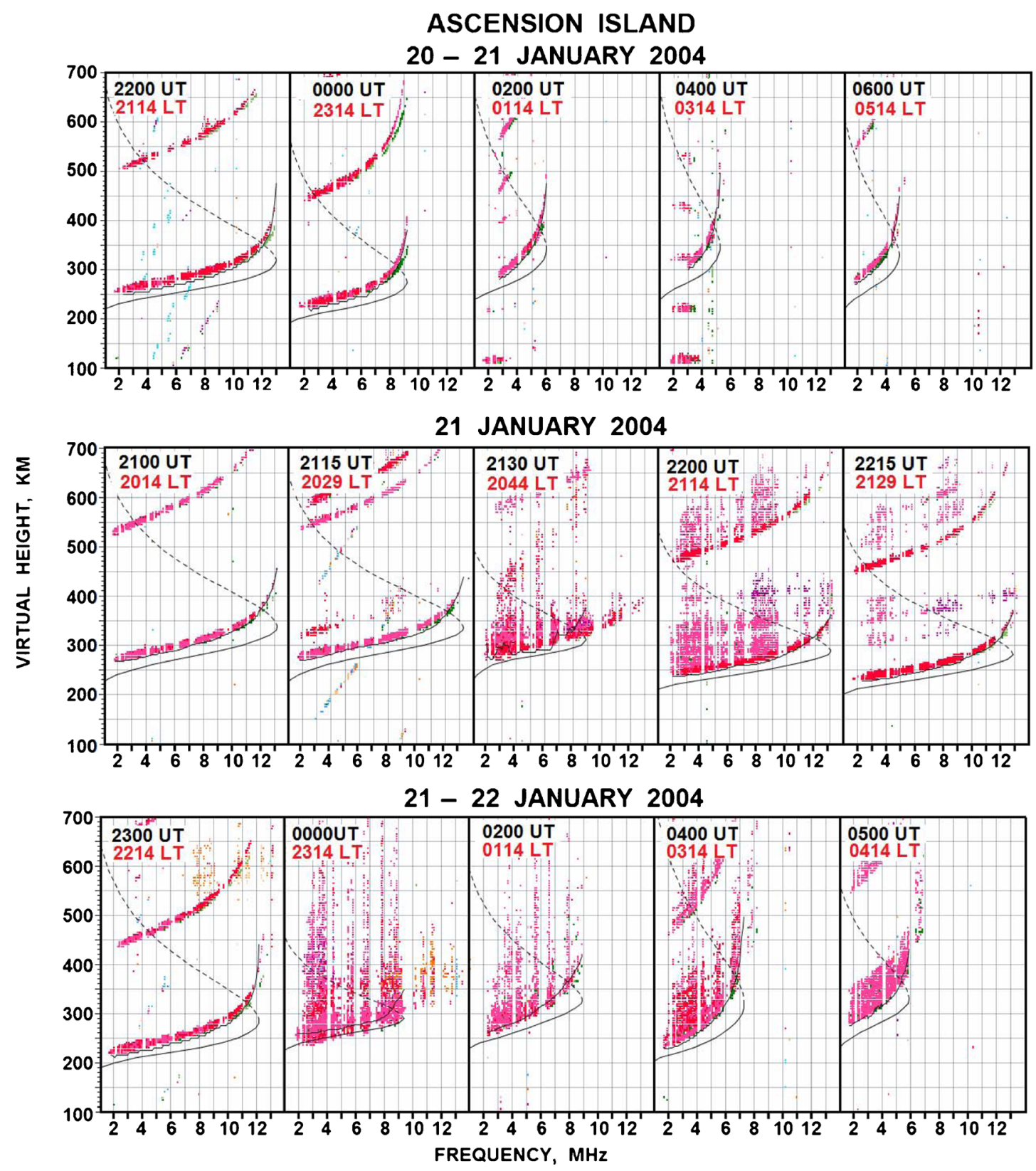

Figure 8. Selected ionograms at Ascension Island during the local nights of January 20-21, 2004 and January 21-22, 2004.

normal post-sunset development of low latitude spread-F. Later, at 2314 LT there was a rise of h'F again and spread-F echoes were recorded thereafter the whole night. This later event was due to the positive excursions of associated IMF-Bz with the magnetic storm.

\subsection{Indian sector $75^{\circ} \mathrm{E}$}

Next pair of equatorial and nonequatorial ionospheric stations available east of ASC were Thumba and Waltair in India. Figure 9 shows the ionograms at Thumba on 21 and 22 January 2004. On 21 January, a very quiet day, the F-region experienced a large post-sunset rise followed by the generation of range type of spread-F at $1430 \mathrm{UT}$ (2000 LT). It is remarkable to note that at 2100 LT very strong range scatterings were recorded at number of altitudes. At later hours the F-layer continued to descend and spread-F vanished after midnight hours.

On 22 January no post-sunset rise of the F-region was seen and no spread-F was recorded. During the first phase prompt penetration electric field was westward that resulted in a very weak electrojet in the Indian sector in the afternoon.

In figure 10 are shown the ionograms at Waltair on the nights of 21 and 22 January 2004. The spread-F at low latitude station is due to field line transmission of irregularities from the equator. On 

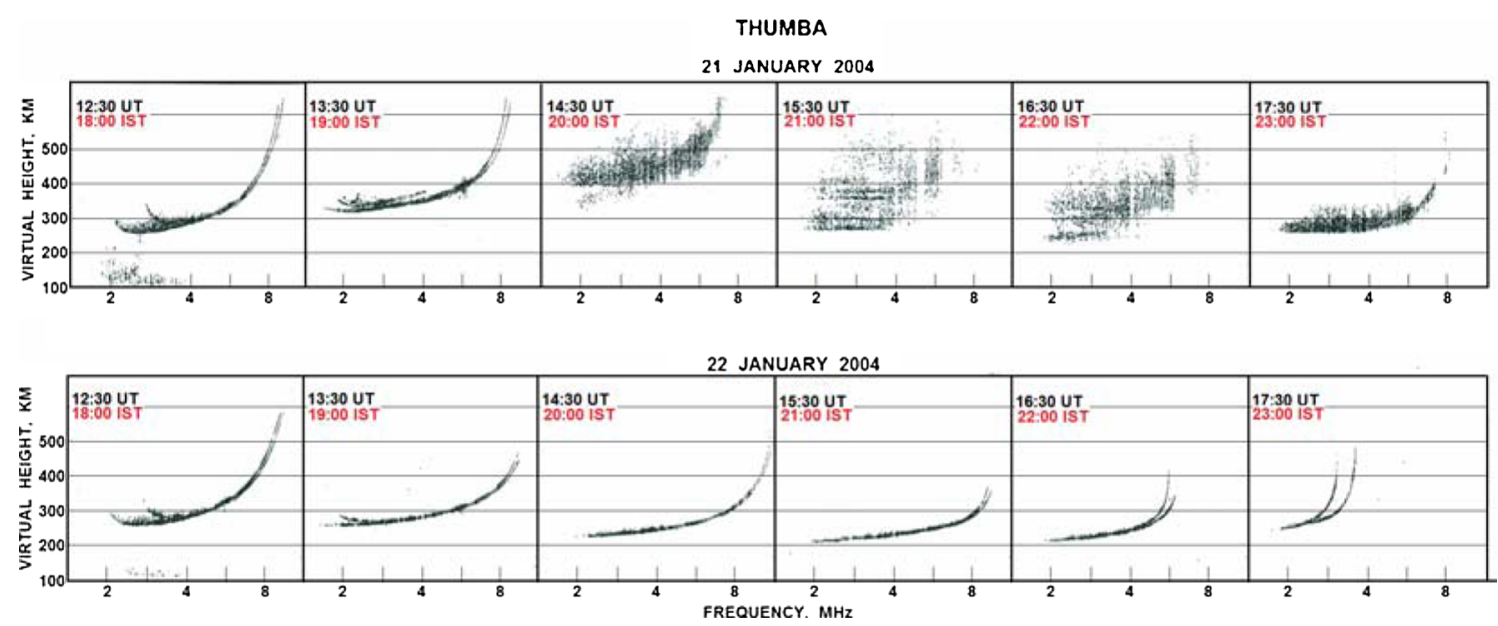

Figure 9. Selected local pre-midnight ionograms at Thumba during January 21-22, 2004.

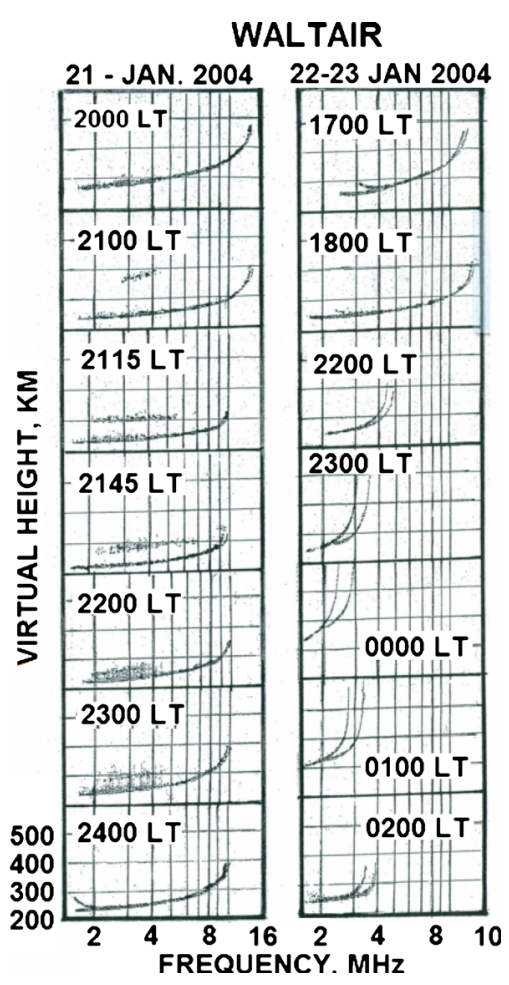

Figure 10. Selected ionograms at Waltair during January 21, 2004 (local pre-midnight) and local night of January 21-22, 2004.

21 January spread-F was recorded first as a satellite trace above the first order echo trace. At later hours the satellite trace moved nearer to first order h'F trace because of the equatorial spread-F irregularities coming closer to the station. At 2200 LT, a good range type of spread-F was recorded at Waltair. No spread-F was observed on 22 January at Waltair as at Thumba.

Further east of Indian longitudes at Chumphon, about an hour east of Thumba, the ionograms at Chumphon on 21 and 22 January 2004 are shown in figure 11. The variations of h' $\mathrm{F}$ and foF 2 on these nights are shown in figure 12 . The height of the F-layer after 1600 LT started increasing till the post-sunset hour of $19 \mathrm{~h}$ LT on 21 January and till 20 LT on 22 January with peak value of 380 $\mathrm{km}$ on both days. The foF 2 showed a post-evening decrease with a minimum at the time when h'F peaks. There was some widening of the first order echo trace on 21 January at 1300 UT (2000 LT) but no range spread-F was recorded on the ionograms. On 22 January too no spread-F were seen.

\subsection{Far east}

Moving further east, we have a pair of equatorial stations, Ho Chi Minh City $\left(106.3^{\circ} \mathrm{E}\right.$ longitude). Figure 13 shows the ionograms at Ho Chi Minh City on the nights of 21 and 22 January 2004 and the variations of foF 2 and h'F on the two nights are shown in figure 14. The usual evening rise of h'F2 continued on 21 January till 1930 LT and on 22 January up to 2030 LT. The foF 2 on 21 January showed usual evening decrease but on 22 January foF2 experienced a large sudden drop after 1900 LT up to 2030 LT. The ionograms on 21 January showed range type of ESF after 1915 LT. On 22 January satellite trace was seen at 1900 LT which developed into ESF at later hours. Thus ESF was seen on both nights at Ho Chi Minh City.

At Ho Chi Minh City (HCM), the first positive IMF-Bz excursions after 0130 UT corresponded to about $09 \mathrm{LT}$. The second phase of the southward turning of IMF-Bz at 1000 UT corresponded to 1730 LT for HCM when the normal processes of the development of spread-F irregularities had already started and ESF were recorded on 22 January 2004.

\subsection{Hainan and Chungli}

Figure 15 shows the ionograms at Hainan $\left(109^{\circ} \mathrm{E}\right)$ and figure 16 shows the temporal variations of $h$ 'F, 


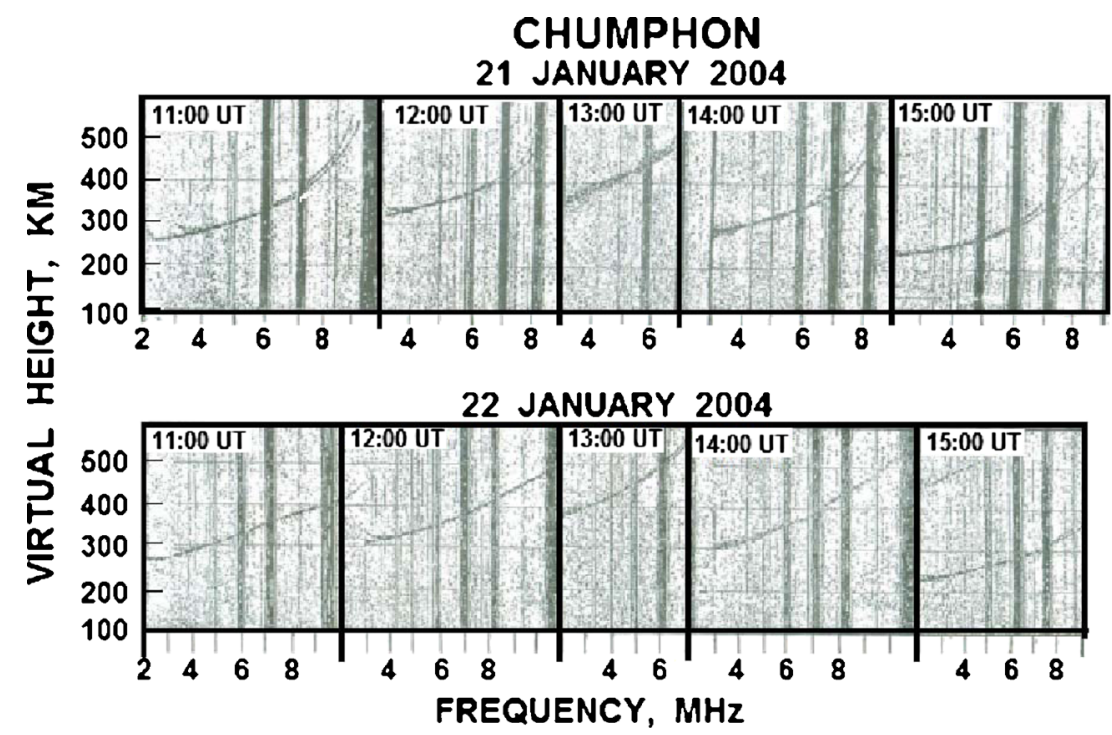

Figure 11. Selected local pre-midnight ionograms at Chumphon during January 21-22, 2004.

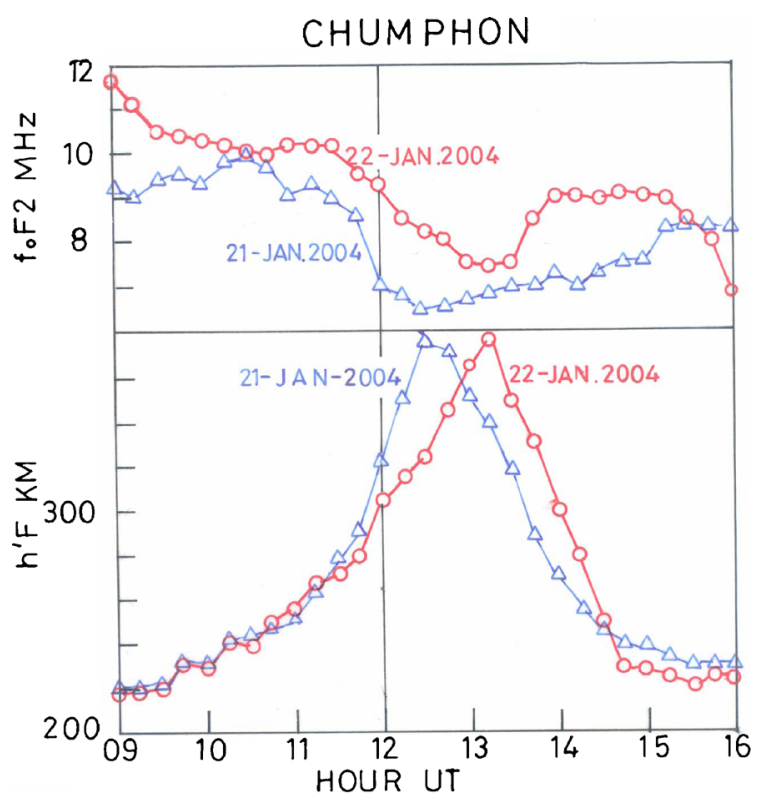

Figure 12. Daily variations of foF2 and h'F at Chumphon during local pre-midnight on 21 and 22 January 2004.

hmF2 and foF 2 on the nights of 21 and 22 January 2004. Hainan and Chung $\mathrm{Li}\left(121.1^{\circ} \mathrm{E}\right)$ are tropical stations where the spread-F is caused due to the movement of irregularities from lower latitudes at later hours after sunset. It is shown in figure 16 that the first spread echoes at Hainan were observed at frequencies beyond foF 2. Thus the spread-F observed at Hainan were the irregularities generated by the positive IMF-Bz during the first phase of the storm at equatorial regions east of the stations and drifted towards it with time reacting around the time of southward turning of IMF-Bz.

\section{HO CHI MINH CITY}

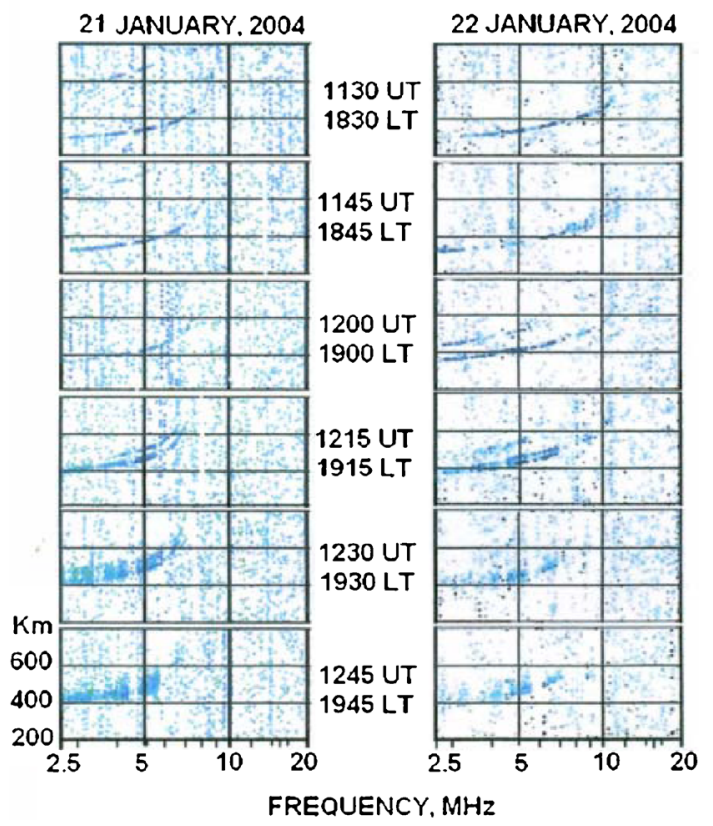

Figure 13. Selected local post-sunset ionograms at Ho Chi Minh City during January 21-22, 2004.

On 21 January there were no major changes in F2 layer parameters, but on 22 January, both h'F and hmF2 showed rise around $1800 \mathrm{LT}$ and foF2 showed unusual rise after 1900 LT. The ionograms on 21 January were very clean and no spread-F were recorded. On 22 January the ionograms were clean at 1857 LT. Later at 1912 LT range type of ESF were seen at the lower frequencies and intensive spread at frequencies beyond foF 2 due to some oblique echoes. At later hours very strong unusual spread-F at different discrete layers were observed during the whole night. 


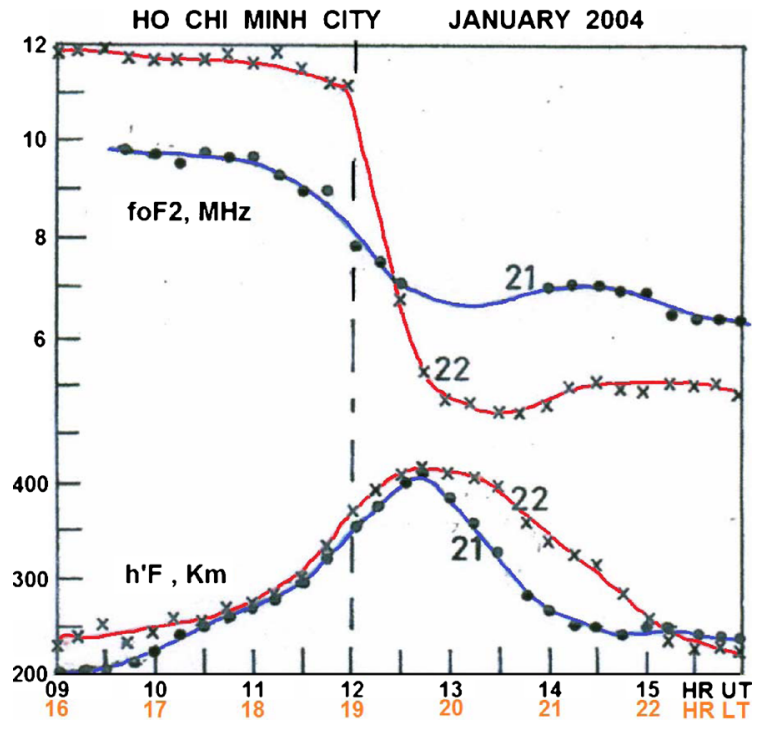

Figure 14. Daily variations of foF2 and h'F at Ho Chi Minh City during local pre-midnight on 21 and 22 January, 2004.

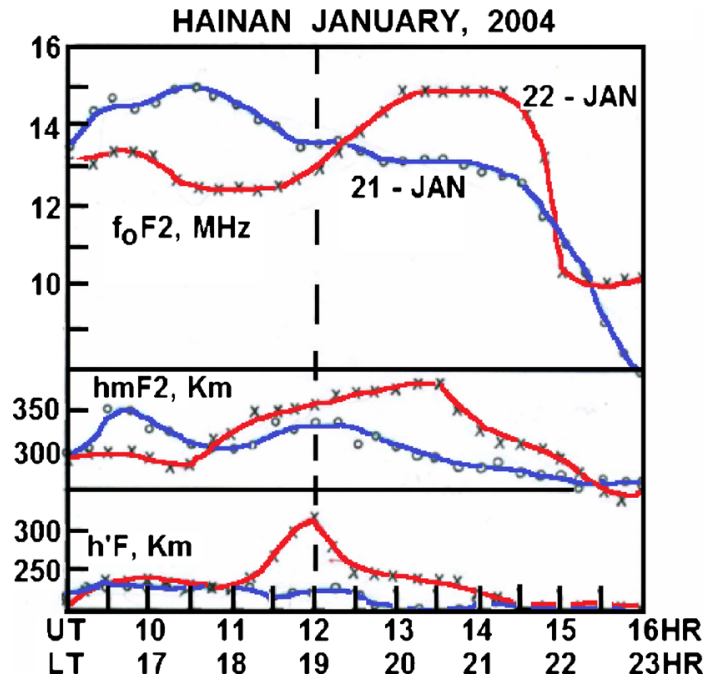

Figure 16. Daily variations of foF2, hmF2 and h'F at Hainan during local pre-midnight on 21 and 22 January, 2004.
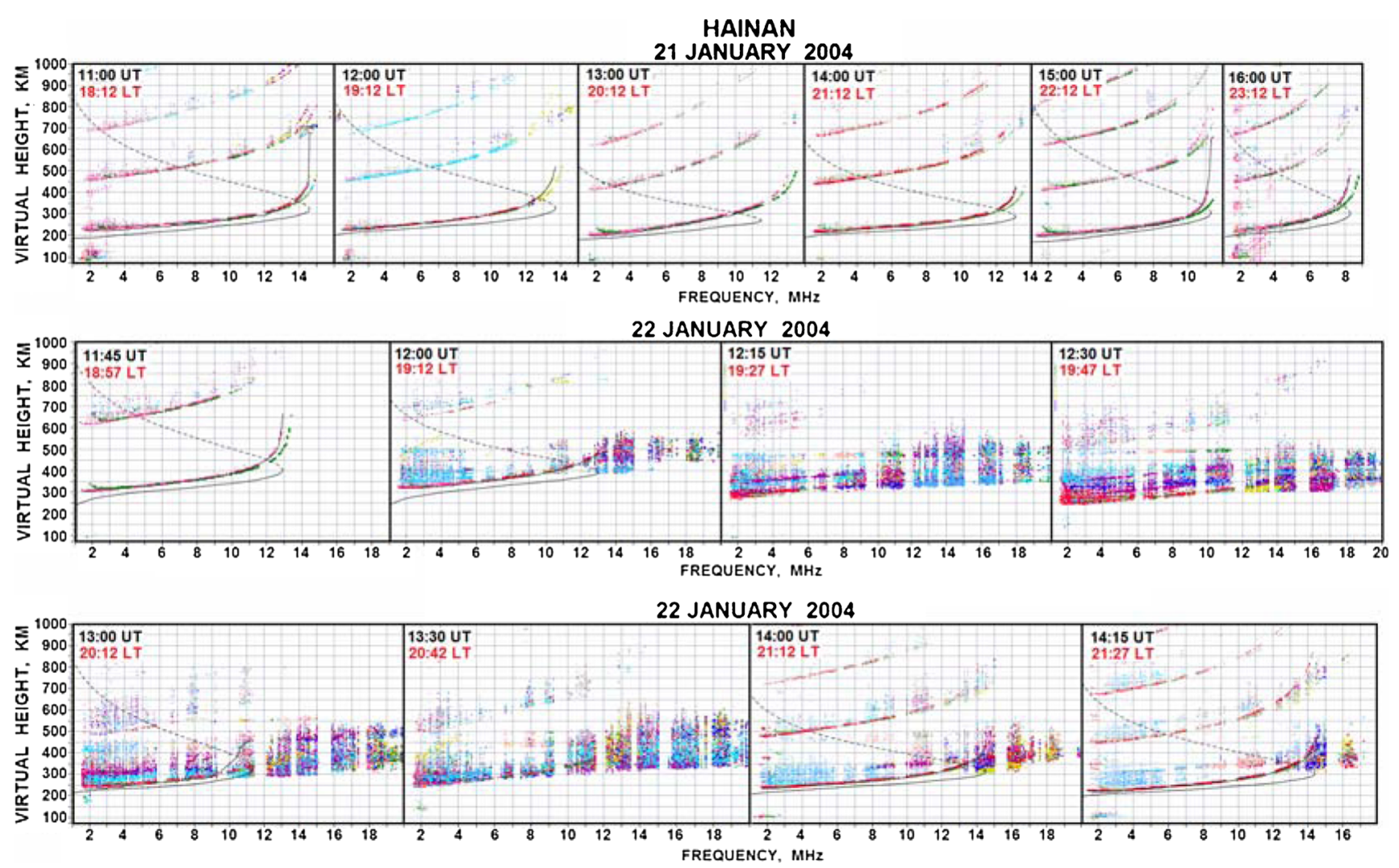

Figure 15. Selected local pre-midnight ionograms at Hainan during January 21-22, 2004.

\section{Discussion}

The magnetic storm of 22 January 2004 had some unusual developments and can be divided into two parts: (i) sudden commencement was at about 0137 UT with the sudden large increase of solar wind speed and density causing an increase of solar wind pressure from 2 to above $15 \mathrm{nPa}$. This was associated with large fluctuations of IMF-Bz averaging positive values. This caused a positive value of ring current index SYM/H. The IMF-Bz was fluctuating (between 0 and $10 \mathrm{nT}$ ) but positive on the 
average with the ring current index of very low average around $-20 \mathrm{nT}$. From about 07 to $10 \mathrm{UT}$ the IMF-Bz was positive. (ii) The second part of the storm started with sudden and large southward turning of IMF-Bz at about $1000 \mathrm{~h}$ UT causing the main phase of the storm with SYM/H decreasing to $-140 \mathrm{nT}$ at $1230 \mathrm{UT}$. The IMF-Bz soon recovered back and remained around $-5 \mathrm{nT}$ thereafter.

The solar wind interaction with magnetosphere is quite a complex process and largely depends on the IMF conditions. The interplanetary and polar electric fields promptly penetrate to equatorial latitudes as dawn-dusk electric fields during the onset and growth phases of a geomagnetic storm with time scales of the order of an hour to several hours. Rapidly changing polar electric fields penetrate to equatorial latitudes unaffected by shielding layer (Kikuchi et al. 1996). The prompt penetrating electric field (under shielding) is eastward on the dayside and westward during night side; therefore it enhances the normal daytime eastward electric field. In the recovery phase of the storm the electric field due to shielding layer penetrates to equatorial latitudes as an over-shielding electric field with opposite polarity, westward during dayside and eastward during night side (Kelley et al. 1979). Thus a northward IMF-Bz (around 08001000 UT on 22 January 2004) would induce an eastward electric field from dusk to dawn, i.e., eastward in the night side and westward in the dayside of the earth. Similarly, a southward turning of the IMF-Bz (after 1000 UT on 22 January 2004) would induce an electric field in the ionosphere from dawn to dusk, i.e., westward in the dayside and eastward during night. Even though the IMF$\mathrm{Bz}$ turned southward very sharply around 1000 UT, it immediately started recovering to northward and may not significantly change the prompt penetration electric field resulting during the first phase.

Looking at the corresponding effects in ionosphere, the impact of the first phase of the storm was strong spread-F seen at both Jicamarca and Sao Luis in the American sector. Spread-F was already present during the night of 21-22 January at Jicamarca but under the impact of the enhanced eastward electric field during the first phase of the storm, F-layer rose from $400 \mathrm{~km}$ at $06 \mathrm{UT}$ to 450 $\mathrm{km}$ at $08 \mathrm{UT}$ and $500 \mathrm{~km}$ at $10 \mathrm{UT}$. The F-layer height movement and spread-F at Sao Luis were as expected on a normal day as the local night times were before the first phase effects.

The impact of the storm during the second phase resulted in the disappearance of Es-q both at Jicamarca (12-14 UT) and Sao Luis (13-15 UT). This is the time when IMF-Bz has almost recovered to north after the sharp southward excursion $(-20$ to $-5 \mathrm{nT})$.
On the eastward longitude side at Ascension Island the development of spread-F on 21 January appears to be normal as seen in the ionograms from 2115 to 2215 UT in figure 8. There were no spread$\mathrm{F}$ echoes at $2300 \mathrm{UT}$, but subsequent ionograms at 0000 to 0500 UT show spread-F following the F-layer rise at $0000 \mathrm{UT}$. This appears to be associated with the northward excursions of IMF-Bz just before midnight UT and then between 01 and 04 UT.

Further east in the Indian zone, there is no spread-F on 22 January 2004 both at Thumba and Waltair. Ionograms in figures 9 and 10 show F-layer descending between 1230 and 1730 UT (local premidnight). This happens due to very weak electric field in the afternoon during the first phase of the storm when prompt penetration electric field was westward.

Further east at Chumphon, there is no apparent effect of the storm. There is evening height rise of the F-layer both on 21 and 22 January but no spread-F echoes were seen. ESF was seen on both nights at Ho Chi Minh City. At Ho Chi Minh City, the southward turning of IMF-Bz at 1000 UT corresponded to $1730 \mathrm{~h}$ LT when the normal processes of the development of spread-F irregularities had already started and ESF were recorded on 22 January 2004. The presence of the spread-F at Hainan appears to be due to the eastward electric field during the first phase of storm (night time eastward field at the station).

Thus the first phase of the magnetic storm of 22 January 2004 (northward turning of IMF-Bz) resulted in strong spread-F at Jicamarca and Sao Luis in the American sector, and at Ascension Island. In the Indian sector there was no spread-F at Thumba and Waltair. Further east there was no spread-F at Chumphon, weak spread-F at Ho Chi Minh City, and strong spread-F at Hainan.

In the dayside ionosphere there was counter electrojet in the American sector due to the second phase (southward turning of IMF-Bz) of the magnetic storm (13-15 UT) and as a consequence no Es-q echoes were seen in ionograms.

\section{Acknowledgements}

Authors thank Physical Research Laboratory, Ahmedabad and Indian Space Research Organization for the facilities for the analysis of datasets recorded by various research centers. RGR is thankful to the Indian National Science Academy for the honorary scientist position. Thanks are due to Indian Institute of Geomagnetism, Navi Mumbai; Space Physics Laboratory, Thiruvanathapuram; Physics Department, Andhra University, Waltair; Institute de Geophysics, Peru; Vietnam Academy of Sciences, Vietnam for providing 
the data. Thanks are also due to $\mathrm{J} \mathrm{H}$ King and N Papitasbvilli at Advel Systems NASA, GSFC and CDA web for the solar wind data and to Space Physics Interactive Data Resources (SPIDR), Boulder, USA; World Data Center for Geomagnetism, Kyoto, Japan; National Institute of Information and Communication Technology, Tokyo, Japan; Digital Ionogram database, Digisonde International, Lovell, USA.

The interplanetary data were obtained from http://cdaweb.gsfc.nasa.gov and the digisonde ionograms from http://ulcar.uml.edu/DiDbase.

\section{References}

Appleton E V 1946 Two anomalies in the ionosphere; Nature (London) 157691.

Balsley B B and Woodman R F 1971 Ionospheric drift velocity measurements at Jicamarca, Peru (July 1967-March 1970); Report UAG-17 World Data Center A, NOAA, Boulder, Colorado.

Bhargawa B N 1958 Observations of spread echoes from the F layer over Kodaikanal - a preliminary study; Indian J. Met. Geophys. 9 35-40.

Booker H G and Wells H W 1938 Scattering of radio waves in the F-region of the ionosphere; Terr. Magn. Atmos. Electr. 43 249-256.

Chandra H 1973 On the disappearance of Es at KodaikanalThumba; J. Inst. Telecom. Engrs. 19 539-544.

Chandra H and Rastogi R G 1972a Spread-F at magnetic equatorial station Thumba; Ann. Geophys. 28 37-44.

Chandra H and Rastogi R G 1972b Equatorial spread-F over a solar cycle; Ann. Geophys. 28 709-716.

Chandra H, Misra R K and Rastogi R G 1971 Equatorial ionospheric drift and the equatorial electrojet; Planet. Space Sci. 19 1497-1503.

Chapman S 1951 The equatorial electrojet as detected from the abnormal electric current distribution above Huancayo, Peru and elsewhere; Arch. Meteorol. Geophys. Bioklimatol A4 368-390.
Gouin P and Mayaud P N 1967 A proposal for the possible existence of a counter electrojet at magnetic equatorial latitudes; Ann. Geophys. 23 41-47.

Kelley M C, Fejer B G and Gonzales C A 1979 An explanation for anomalous ionospheric electric field associated with a northward turning of the interplanetary magnetic field; Geophys. Res. Lett. 6 301-304.

Kikuchi T H, Luhr T, Kitamura T, Saka O and Schliegel K 1996 Direct penetration of the polar electric field to the equator during a DP2 event as detected by the auroral and equatorial magnetometer chains and the EISCAT radar; J. Gephys. Res. 101 17,161-17,173.

Knecht R W 1959 An additional lunar influence on the equatorial Es at Huancayo; J. Atmos. Terr. Phys. 14 348-349.

Li G, Nang B, Lue L, Wan W and Liu J Y 2009 Effect of magnetic activity on plasma bubbles over the equatorial and low-latitude regions in East Asia; Ann. Geophys. 27 303-312.

Lyon A J, Skinner N J and Wright R W H 1961 Equatorial Spread F at Ibadan, Nigeria; J. Atmos. Terr. Phys. 21 100-119.

Matsushita S 1951 Intense ionizations near the magnetic equator; J. Geomagn. Geoelectr. 3 44-46.

Osborne B W 1952 Ionospheric behavior in the F2 region at Singapore; J. Atmos. Terr. Phys. 2 66-78.

Rastogi R G 1977 Equatorial Spread F and the interpl anetary magnetic field; J. Geom. Geoelectr. 29 557-561.

Rastogi R G 1980 Seasonal variation of equatorial spread $\mathrm{F}$ in the American and Indian zones; J. Geophys. Res. 85A2 722-726.

Rastogi R G 1983 Tropical spread F; Indian J. Radio Space Phys. 12 101-113.

Rastogi R G and Chandra H 1974 Interplanetary magnetic field and the equatorial ionosphere; J. Atmos. Terr. Phys. 36 377-379.

Rastogi R G and Patel V L 1975 Effect of interplanetary magnetic field on the ionosphere over the magnetic equator; Proc. Indian Acad. Sci. 82(A4) 121-141.

Rastogi R G and Woodman R F 1978 Spread-F in equatorial ionograms associated with the reversal of horizontal $\mathrm{F}$ region electric field; Ann. Geophys. 34 31-36.

Rastogi R G, Chandra H and Chakravarty S C 1971 The disappearance of equatorial Es and the reversal of equatorial electojet current; Proc. Indian Acad. Sci. 74 62-67. 